\title{
Germany's 'blue-list' gets tougher judgement
}

Munich. Eighty-two research institutes in Germany, known collectively as 'blue-list' institutes, are to be given a stronger umbrella organization and a formal system of evaluation that will make it more difficult for poor performers to use political backing to protect themselves against closure.

Blue-list institutes - named for the colour of the paper on which the original list was printed - carry out a range of research activities, from low-temperature plasma physics to tropical medicine.

The cost of each institute is shared by its home Land and one of ten federal ministries. But they have never fitted comfortably within the German basic research system, which has three major pillars - the universities, the Max Planck Gesellschaft (MPG) and the national research centres.

Difficulties started after the reunification of Germany, when 34 establishments of the former East Germany were accepted as bluelist institutes on the recommendation of the science advisory council, the Wissenschaftsrat. Each was felt to be too small to become a national research centre; but neither the MPG nor the universities - as had been hoped - were prepared to absorb them.

As a result, the number of such institutes increased from 48 to 82 and their budget, currently DM1.16 billion (US\$700 million) a year, began to rival that of the MPG (see Nature 363, 482; 1993). Critics say there are now too many blue-list institutes, and that they should be made to fit into the conventional research establishment. But Gerhard Neuweiler, head of the Wissenschaftsrat, has long disagreed.

He has wanted their small umbrella or- ganization, the AG-BL, which was set up in January 1992 , to assume similar powers to those of the MPG, which controls not only its own budget and the scientific direction of the society as a whole, but also, through a rigorous system of evaluation, the standard of research in its individual institutes. This, he says, would allow money to be shifted away from institutes that perform badly.

Until now, evaluations of blue-list institutes have been carried out on request by the Wissenschaftsrat. Neuweiler says that in the past, negative evaluations have been met with political pressure either from the host Land, keen to retain research institutes that enjoy federal support, or from the relevant ministry, reluctant to lose the prestige of its own research institute.

But there has also been resistance to the idea that the blue-list institutes should have more power and status. The Wissenschaftsrat had to accept a compromise. But this will still allow the AG-BL to enlarge its secretariat and set up a permanent base.

The AG-BL will probably be based in Cologne, the home of the Wissenschaftsrat.

It is now planning to set up a scientific section to guide its research portfolios, and to carry out systematic evaluations of its institutes through the Wissenschaftsrat, starting in the new year.

In order to reduce political influence on decisions about which institutes should be supported, the Wissenschaftsrat has introduced a new procedure under which the original scientific assessment of each evaluation committee will accompany the final recommendation of the Wissenschaftsrat, and will therefore be made public. The Wissenschaftrat is setting up a standing committee to organize evaluations, a move which will double its workload.

Neuweiler hopes that, with the new arrangements, arguments over the continued existence of the blue-list institutes will cease. "Two years ago the Wissenschaftsrat promised a good future to scientists in blue-list institutes in the new Länder," he says. Neuweiler adds: "We can't say now that we have second thoughts". But he admits that there remains some "hidden pressure" to say just that.

Alison Abbott

\section{Trial deaths prompt tighter rules}

Washington. The Food and Drug Administration (FDA) is to tighten up its clinical drug trial regulations following a trial of a treatment for hepatitis-B carried out by the National Institutes of Health (NIH) earlier this year in which five patients died of liver failure (Nature 364, 275; 1993).

New regulations being drawn up by the FDA will make drug companies who sponsor trials responsible for gathering informa-

\section{Biologist to head US Forest Service}

Washington. US conservationists have enthusiastically welcomed the appointment of a wildlife biologist, Jack Ward Thomas, as chief of the Department of Agriculture's Forest Service. But representatives of the timber industry are furious that Thomas, who has worked with the Forest Service as a wildlife biologist for 27 years, has been chosen to fill a key post previously held by career forest managers.

As a prominent researcher associated with moves to restrict tree felling, Thomas has been an active participant in a passionate debate over forestry policy, especially in the northwestern United States. Even before his promotion, he had travelled in the company of bodyguards and had received a number of death threats.
In 1990 , Thomas chaired the panel that revealed the threat posed by the activities of the timber industry to the survival of the spotted owl in the northwest. His appointment seems certain to Jack Ward Thomas mark a clear shift in the Forest Service's first priority, from timber production to nature conservation. "Thomas represents a new generation of managers, fully committed to maintaining biological diversity", says Stuart Pimm, professor of ecology at the University of Tennessee. C. M. tion on side effects from all previous safety and efficacy trials of the drug in question, and for looking for patterns of toxicity.

The regulations were recommended in a report by an FDA task force into the immediate lessons of the trial, which used the drug Fialuridine. An internal NIH investigation has already ruled that NIH procedures were fully complied with. But in response to Congressional concern, health secretary Donna Shalala has asked the Institute of Medicine to conduct a full, independent review of the trial.

The five died when the drug was used on fifteen patients in a trial conducted by the National Institute of Diabetes and Digestive and Kidney Diseases (NIDDK) and sponsored by the company Eli Lilly.

The report examined data from six previous clinical trials of Fialuridine, and found that problems arising in them were attributed to causes other than the drug's toxicity.

But the report finds that a "worst case" analysis of all deaths and adverse effects associated with previous trials could have detected the drug's toxicity before the fateful trial took place. The FDA report also notes that the natural optimism of investigators and sponsors can lead them to miss evidence of toxicity.

The task force, having recommended changes to existing regulations. is now investigating whether the NIDDK research team, led by Dr Jay H. Hoofnagle, breached old FDA rules in its conduct of the trial. 